\title{
Longing for better ultrasound-guided subclavian/axillary venous cannulation
}

\section{Gentle Sunder Shrestha}

Ultrasound guidance for central venous catheter (CVC) placement reduces complications, increases safety and enhances the quality of the procedure [1]. Existing guidelines suggest a higher level of evidence for ultrasound-guided internal jugular venous cannulation compared with the subclavian/axillary route [2]. Meta-analysis of trials studying the use of ultrasound guidance for subclavian venous cannulation, when compared with the landmark technique, showed decreased incidence of arterial puncture and hematoma formation, but there was no overall difference in complications and success rates [3].

Smaller studies have shown that patient positioning during cannulation of the subclavian vein (e.g., turning the head to the contralateral side, shoulder-pulled-downward position, and abducted position of arm) can alter the relationship between the subclavian vein and the internal jugular vein and can also alter the cross-sectional area of the vein, thus potentially affecting the safety and success of cannulation $[4,5]$. Further well designed studies should try to explore the influence of these various patient positions on ultrasound-guided subclavian venous cannulation.
Received: 29 April 2018 Accepted: 21 May 2018

Published online: 05 June 2018

\section{References}

1. Saugel B, Scheeren TWL, Teboul JL. Ultrasound-guided central venous catheter placement: a structured review and recommendations for clinical practice. Crit Care. 2017;21:225.

2. Frankel HL, Kirkpatrick AW, Elbarbary M, et al. Guidelines for the appropriate use of bedside general and cardiac ultrasonography in the evaluation of critically ill patients - part I: general ultrasonography. Crit Care Med. 2015:43:2479-502

3. Brass P, Hellmich M, Kolodziej L, Schick G, Smith AF. Ultrasound guidance versus anatomical landmarks for subclavian or femoral vein catheterization. Cochrane Database Syst Rev. 2015;1:CD011447.

4. Ahn JH, Kim IS, Shin KM, et al. Influence of arm position on catheter placement during real-time ultrasound-guided right infraclavicular proximal axillary venous catheterization. Br J Anaesth. 2016;116:363-9.

5. Sadek M, Roger C, Bastide $\mathrm{S}$, et al. The influence of arm positioning on ultrasonic visualization of the subclavian vein: an anatomical ultrasound study in healthy volunteers. Anesth Analg. 2016;123:129-32.

\section{Abbreviation}

CVC: Central venous catheter

Authors' contributions

GSS contributed to the concept, design, literature search, manuscript writing, editing, and review. The author read and approved the final manuscript.

\section{Competing interests}

The author declares that he has no competing interests.

\section{Publisher's Note}

Springer Nature remains neutral with regard to jurisdictional claims in published maps and institutional affiliations. 